\title{
Becoming physics people: Development of integrated physics identity through the Learning Assistant experience
}

\author{
Eleanor W. Close, Jessica Conn, and Hunter G. Close \\ Department of Physics, Texas State University, San Marcos, Texas 78666, USA
}

(Received 1 December 2014; published 22 February 2016)

\begin{abstract}
[This paper is part of the Focused Collection on Preparing and Supporting University Physics Educators.] In this study, we analyze the experience of students in the Physics Learning Assistant (LA) program at Texas State University in terms of the existing theoretical frameworks of community of practice and physics identity, and explore the implications suggested by these theories for LA program adoption and adaptation. Regression models from physics identity studies show that the physics identity construct strongly predicts intended choice of a career in physics. The goal of our current project is to understand the details of the impacts of participation in the LA experience on participants' practice and selfconcept, in order to identify critical elements of LA program structure that positively influence physics identity and physics career intentions for students. Our analysis suggests that participation in the LA program impacts LAs in ways that support both stronger "physics student" identity and stronger "physics instructor" identity, and that these identities are reconciled into a coherent integrated physics identity. Increased comfort in interactions with peers, near peers, and faculty seems to be an important component of this identity development and reconciliation, suggesting that a focus on supporting community membership is useful for effective program design.
\end{abstract}

DOI: 10.1103/PhysRevPhysEducRes.12.010109

\section{INTRODUCTION}

In this paper we analyze the experience of undergraduate students in the Physics Learning Assistant (LA) program at Texas State University for evidence of how participation in the LA program has affected elements of LAs' identity, in what ways and through what program elements. Our analysis draws from the existing theoretical frameworks of communities of practice [1-3] and physics identity [4,5] and establishes connections between identity as understood through participation in practice and identity as self-perception.

The LA program at Texas State University is based on the model developed at the University of Colorado Boulder (CU-Boulder) [6] and the successful LA program at Seattle Pacific University [7], and supports course reform in the introductory calculus-based physics sequence. Previous research has documented a number of positive impacts of the LA experience. The LA programs at CU-Boulder and Seattle Pacific University have been highly successful at recruiting physics and other science, technology, engineering, and mathematics (STEM) majors into K-12 teaching $[6,7]$. In courses with LAs, both the LAs and the students enrolled in the course demonstrate increased conceptual

\footnotetext{
*Corresponding author. eclose@txstate.edu

Published by the American Physical Society under the terms of the Creative Commons Attribution 3.0 License. Further distribution of this work must maintain attribution to the author(s) and the published article's title, journal citation, and DOI.
}

understanding of the content; in addition, LAs have been shown to experience a large positive shift in overall attitudes about science, and a particularly large shift in the "personal interest" category, as measured by the Colorado Learning Attitudes about Science Survey $[6,8]$. A study by Gray, Webb, and Otero [9] found that former LAs who become precollege teachers are more successful at implementing research-based teaching in their first year as K-12 science teachers than are non-LAs who completed the same certification program.

The bulk of existing studies of the LA experience are focused on quantitative measures comparing the final states of LAs to their initial states or to the final states of similar non-LAs. Our intent in this study is to complement existing work by examining the process of transformation: What is happening during the LA experience that leads to the outcomes measured in other studies? How do students describe their experiences in the LA program, and how do they evaluate the meaning and impact of the various elements of their experience? We hope that this analysis will provide insight into both the details of the LA experience, as it is lived by Texas State students, and the mechanisms by which structures of LA program implementation support student transformation.

\section{CONTEXT}

\section{A. University and physics program background}

Texas State University is an Hispanic Serving Institution with approximately 37000 students, of whom about 32000 
are undergraduates. Texas State is the largest Hispanic Serving Institution in Texas and the fifth-largest university in the state. The university is currently in transition from a teaching-focused university to an "emerging research university" (as reclassified by the Texas Higher Education Coordinating Board in 2012), and has grown in enrollment about $3 \%$ annually for several years. The undergraduate student body is increasingly diverse: currently $43 \%$ are racial or ethnic minorities, including 33\% Hispanic (up from $24 \%$ five years ago) and $10 \%$ African American (up from $6 \%$ five years ago). Among undergraduate students, $56 \%$ are female, a proportion that has been steady over the past decade.

There are currently 111 declared physics majors enrolled at Texas State. In 2011, 2012, and 2013, the department granted 14, 8, and 10 B.S. degrees, respectively. Of the currently declared physics majors, approximately $12 \%$ are female (more than in the previous few years, but the same percent as five years ago), 27\% Hispanic (up from 12\% five years ago), and $7 \%$ African American (up from 5\% five years ago).

Enrollment in introductory physics courses has grown significantly over the past five years, influenced in part by the rising profile of the Ingram School of Engineering, for which the enrollment has grown at an even higher rate than that of the university as a whole (from 100 enrolled majors in 2004 to over 800 in 2014). In Fall 2014 the calculusbased introductory physics sequence in which LAs assist enrolled approximately 250 students in the first course (mechanics), 200 in the second course (electricity and magnetism), and 50 in the third course in the sequence (waves and heat, required only of physics and electrical engineering majors). The proportions of minority students in the introductory courses match the proportions in the overall undergraduate population, and the gender distribution in the courses is similar to that of the physics major (20\% women in the first two courses in the sequence, $12 \%$ women in the third course). The course sequence is dominated by engineering majors: in the first two courses in the sequence, approximately $5 \%$ of the students are physics majors, $60 \%$ are engineering majors, $20 \%$ chemistry or biochemistry majors, and $10 \%$ other STEM majors; in the third course in the sequence, $25 \%$ are physics majors and $60 \%$ are electrical engineering majors.

\section{B. Learning Assistant program description}

The LA program at Texas State is modeled on the highly successful physics LA program at Seattle Pacific University, which was developed and led in part by $\mathrm{H}$. Close and E. Close [7]. Texas State LAs are constantly mentored, supported, and accompanied by faculty as they help faculty interactively teach during universitydesignated "lecture time." Core program faculty emphasize the importance of community and mutual support among physics students and faculty, and communicate regularly to LAs about ways in which the program is intended to benefit them (both intellectually and socially) and benefit the introductory students.

LAs currently assist in all sections of introductory calculus-based physics: five sections of mechanics, four sections of electricity and magnetism, and one section of waves and heat per semester. Each section enrolls about 50 students. Faculty have elected to introduce interactive reforms-mostly through the introduction of Tutorials in Introductory Physics [10] and other similar materials-in the lecture sections and some laboratory sections, rather than in separate recitation sections, which currently do not exist at Texas State. The program has grown to its present scale gradually over the course of the past three years, beginning in one section of mechanics in Spring 2012.

In addition to assisting in class, many LAs work in the Physics Help Center, a walk-in tutoring center located near physics faculty offices, open $35 \mathrm{~h}$ a week and staffed entirely by LAs. Most LAs work in the Help Center for at least an hour each week, and the Help Center is staffed by two LAs during most hours; the Help Center therefore provides an additional shared teaching experience for the majority of LAs. In addition, since implementing tutorials [10] in the laboratory for the calculus-based mechanics course, the physics department preferentially hires LAs as laboratory instructors for this course. Approximately 50\% of LAs each semester instruct mechanics laboratory sections, which provides a more independent teaching experience in parallel with the highly supported work in lecture sections and the one-on-one work in the Help Center.

Currently, the pedagogy component of the LA program consists of the course PHYS 3210: Physics Cognition and Pedagogy, taught by E. Close. This course includes readings and discussions about constructivism, metacognition, discipline-based education research studies [11-13], and gender bias and stereotype threat in science; discussion emphasizes implications and applications of the concepts or research results from the readings for LAs' experiences both as co-instructors and as students. LAs also work in pairs to perform a series of two clinical interviews, following the Physics Interview Project developed by H. Close at Seattle Pacific University [14], for which the purpose is to develop listening skills for use in the practice of teaching physics. This course counts as an upperdivision physics elective and satisfies the writing intensive credit requirement.

Applicants for the LA position each semester are required to have successfully completed the first course in the introductory sequence; the LA selection process prioritizes interest in education (either as a K-12 teacher or as a researcher in physics education), interest in physics as a major, academic achievement in physics courses (grades of $\mathrm{A}$ and $\mathrm{B}$ are equally acceptable), and recommendations from faculty and current LAs regarding applicants' communication skills and facility with productive small-group 
interactions. Students of all majors are encouraged to apply, and faculty make an effort to recruit women and students from underrepresented minorities.

The Physics Learning Assistant Program provides a substantial early teaching experience for between 30 and 40 participants each year (25-30 participants each semester, of whom some are returning or experienced LAs). Representation of women is higher in the LA program than in the physics major: physics majors are approximately $12 \%$ women; over the past three semesters, between $25 \%$ and $39 \%$ of LA program participants have been women. Representation of Hispanic and African American students in the LA program approximately matches representation in the physics major: over the past three semesters, between $24 \%$ and $32 \%$ of LAs have been Hispanic, in comparison with $27 \%$ of majors; and between $5 \%$ and $12 \%$ have been African American, in comparison with $7 \%$ of majors.

\section{THEORETICAL FRAMEWORK}

In this section, we give a brief overview of relevant elements of the two theoretical frameworks used in our analysis and build a correspondence between factors in the physics identity framework and community of practice theory. In Secs. III A-III C, we use this blended theory to analyze written artifacts produced by LAs and videos of LA interviews.

\section{A. Identity in practice}

Lave and Wenger developed a socially situated theory of learning centered on relationships between learning, identity, and practice [1-3]. In this theory, practice refers to sustained engagement in a joint enterprise: not only doing something (e.g., practicing a task), but participating in an enterprise that is collectively constructed within a particular social context.

A well-functioning community of practice is defined by "mutual engagement, a joint enterprise, and a shared repertoire" (Ref. [1], p. 73); participation in the community shapes and is shaped by the ways in which members of the community engage each other around their shared practice. Through this mutual engagement, members negotiate and define their joint enterprise, which encompasses explicit goals as well as ways of being and relating that may not be articulated (e.g., use of particular representations). Over time, the community develops a shared repertoire of resources for negotiating meaning, including ways of accomplishing tasks, styles of interacting, tools, language, concepts, and stories. Membership in communities of practice provides structure to a person's lived identity by shaping their perceptions, values, and interactions with others.

Development of an identity as a member of an existing community of practice requires the possibility of moving from newcomer status in the community toward full membership, what Lave calls "a social process of increasingly centripetal participation" (Ref. [2], p. 68). This is best facilitated through "legitimate peripheral participation," in which newcomers engage in tasks that are important to the community of practice and that give the novices access to situations in which they can observe and interact with more central participants. Newcomers whose practice is isolated from the rest of the community (i.e., not peripheral) or whose tasks do not authentically contribute to the joint enterprise are unable to develop identities of mastery. According to Lave, communities of practice that successfully reproduce themselves are characterized by "newcomers furnished with comprehensive goals, an initial view of the whole, improvising within the multiply structured field of mature practice with near peers and exemplars of mature practice" (Ref. [2], p. 72). In this theory, learning is not an individual, internal process, nor is it a social process that results in an individual, internal change; rather, it is inherent in the process of becoming a member of a community of practice.

Lave and Wenger describe development of identity and participation in communities of practice as deeply intertwined $[1,3]$. Identity, as shaped by engagement in practice, is not an inherent or fixed quality of a person but rather a process of continuous renegotiation. The relationship between identity and membership in communities of practice is that of competence: participation in the joint enterprise of the community leads to particular forms of competence and ways of engaging. Wenger states, "In practice, we know who we are by what is familiar, understandable, usable, negotiable" (Ref. [1], p. 153). Identity in this theoretical framework includes but is not limited to self-image (the ways we describe ourselves). Reflective (self-described or self-reported) aspects of identity are relevant but do not encompass the full complexity of lived identity: "Who we are lies in the way we live day to day, not just in what we think or say about ourselves" (Ref. [1], p. 151).

Wenger [1] identifies five characterizations of identity in practice, four of which we find relevant to the current study. These are not components of identity in the sense that some theoretical constructs attempt to define mutually orthogonal elements of the whole; rather, these characterizations are overlapping ways of understanding identity through the lens of participation in shared practice. The characterizations we will explore in this study are identity as negotiated experience, as community membership, as learning trajectory, and as nexus of multimembership. We will discuss these characterizations in more detail in Sec. III C.

\section{B. Physics identity self-concept}

In two studies including data from over 10000 college students, Hazari and colleagues developed and empirically validated a theoretical framework for physics identity, 
drawing on the science identity framework by Carlone and Johnson [15]. The physics identity framework was initially composed of four elements: personal interest, student performance, competence, and recognition by others $[4,5]$. The data consisted of responses to survey items on the Persistence Research in Science and Engineering (PRiSE) survey [4] and the Sustainability and Gender in Engineering (SaGE) survey [5], which were administered to students in introductory English courses in a nationally representative sample of colleges and universities. Assessment of physics identity in these studies is based on self-report, e.g., the dimension competence can be described as "belief in ability to understand physics content," while performance is "belief in ability to complete physics tasks." Factor analysis indicated that performance and competence formed a single factor in student responses; therefore, the physics identity framework was simplified to include the three elements: personal interest, performance or competence, and recognition by others. We use this simplified framework in our analysis.

Regression models from these studies show that the physics identity construct strongly predicts intended choice of a career in physics [4,5]. The studies also probed classroom experiences supportive of student physics identity development. Student self-reports of engaging in expertlike behaviors in physics class, such as responding to questions and teaching peers, were found to be strong predictors of physics identity; Hazari et al. note that instructors play a role in facilitating this behavior through establishing a classroom culture that "minimizes the anxiety of public expression," acknowledges students' ideas, and allows learning struggles to be visible rather than hidden (Ref. [4], p. 996). In addition, some instructional factors correlated positively with physics identity development, including a focus on conceptual understanding, laboratory experiences addressing students' beliefs about the world, and instructor encouragement to take more science classes (Ref. [4], p. 995).

\section{Relating self-concept and practice}

In order to relate the empirically tested physics identity framework to broader identity concepts from community of practice theory, we build a correspondence between factors. Wenger [1] describes identity as negotiated experience as the process of making meaning from the encounters and experiences of participation in a community of practice. This is summarized in the following way: "We define who we are by the ways we experience our selves through participation as well as by the ways we and others reify our selves" (Ref. [1], p. 149). The meaning we make of our experience is shaped by how others respond to us-how we "encounter our effects on the world"- and by the characteristics and relations the community values and recognizes. The physics identity dimension of (self-reported) recognition, as measured through survey items such as "my physics teacher sees me as a physics person" and "my friends see me as a physics person" [5], describes an element of this characterization of identity. Self-image is a component of negotiated experience, but not the entirety: self-image is a reification involving labels such as "physics person" and "Learning Assistant," while identity through negotiated experience encompasses the interaction of these reifications with the experiences of participation in the community.

Community membership defines identity through the forms of competence developed and valued by participants in the community of practice, including ways of interacting and working together, shared perspectives, and ability to make use of a shared repertoire of tools, language, stories, and other resources. A self-reflection on identity characterized in this way might include "do I know how to do things this community values?" This characterization encompasses the physics identity dimension of performance or competence, which is measured through responses to survey items such as "I understand concepts I have studied in this subject" and "Others ask me for help in this subject" [5]. The link between identity and competence demonstrated by engagement in expertlike behavior is consistent with the characterization of identity in practice as community membership.

Identity as learning trajectory incorporates past identities and possible futures into making meaning of the present; as described above, identity is constantly renegotiated, and changes in our identity over time build a sense of where we have been and where we are going. Participation in a community impacts an individual's identity when the practice of the community incorporates that person's past and fits into a valued future. Trajectory influences what elements of participation are perceived as important and what are marginal. This characterization encompasses the physics identity dimension of personal interest, as measured through survey items such as "I enjoy learning this subject" and "I am interested in learning more about this subject" [5]. It is also consistent with the positive relationship between instructional laboratory experiences addressing students' beliefs about the world and students' development of physics identity, because these instructional experiences validate past lived experiences as relevant for present learning.

Individuals are members of multiple communities of practice. Identity as nexus of multimembership is characterized by the work of reconciling practices of membership in different communities. This work is often challenging: Wenger notes that "learners must often deal with conflicting forms of individuality and competence as defined in different communities" and "elements of one repertoire may be quite inappropriate, incomprehensible, or even offensive in another community" (Ref. [1], p. 160). In previous analysis [16-18], we describe the LA program as creating an overlap between the community of practice of 
STEM majors and that of physics instructors, with LAs experiencing membership in both communities and creating overlap between the practices of each. In addition to these two communities of practice, in which all LAs participate, each LA has other communities and other practices that must be reconciled in their enacted identity. Our current analysis is focused on common themes and shared experiences across the community of LAs.

\section{METHODS}

Our intent in this study is to examine the process of transformation that occurs through participation in the LA program. Our driving questions are about students' experience(s) of participation: What is happening during the LA experience that could lead to the outcomes measured in other studies? How do students describe their experiences in the LA program, and how do they evaluate the meaning and impact of the various elements of their experience? This section describes the data sources and methods of analysis used in order to investigate these questions.

\section{A. Data sources}

Data for this study are drawn from several forms of writing produced by LAs as well as from video records of interviews with a subset of experienced LAs. Written data are gathered from multiple sources, including teaching reflections and program applications. In this section we describe each source of data: the context in which the data are gathered, the prompts to which LAs respond, and the methods by which the prompts are administered and the data are collected. Examples of data from written sources are reproduced in italics, while those from interviews are not italicized.

\section{Teaching reflections}

Teaching reflections are assigned as part of the required pedagogy course for new LAs, and are submitted to an online forum on the course management website. In addition to posting their own reflections, students are required to read and respond to at least one post made by another student. The number and timing of assigned reflections and the assigned reflection prompts have varied from semester to semester; for the past few semesters, reflections have been assigned approximately every two weeks. Some reflection prompts ask LAs to relate assigned readings to their teaching experiences or observations (e.g., "What RTOP items do you think are most relevant to you in your role as LA, and why?" [19]; other prompts ask them to reflect on their own expectations for teaching (e.g., "What do you expect will be the most interesting thing about teaching as an LA?") or their perceptions of their own strengths, difficulties, and growth (e.g., "What are you finding particularly challenging right now in your LA role?" and "Reflect on your teaching interactions now as compared to the start of the semester. What have you gotten better at over the past two months?"). Grading criteria for these reflections are limited to length (meeting the assigned minimum number of words), timeliness, and whether or not the reflection prompt has been addressed; content is not critiqued as part of the grade.

For this study, we analyzed over 180 reflection forum postings from 61 unique LAs over five semesters of the pedagogy course (Fall 2012 through Fall 2014). Our analysis focused primarily on the first and last reflection assignments each semester, because the reflection prompts in these cases focused on initial expectations and on how the LA experience compared to those expectations.

\section{Program applications}

Students interested in participating in the LA program must apply to the program near the end of each semester in order to serve as an LA the following semester. LAs complete different applications if they are applying to be admitted to the program for the first time (new LAs) or for readmission after one or more semesters of participation in the program (returning LAs). Applications are completed through the SurveyMonkey online survey tool; completed applications are downloaded from the Web site and saved on a secure university server. The returning LA application includes open-ended questions such as "Why do you want to continue to be an LA?," "What is your opinion of your performance as an LA this semester?", and "What have you learned from being an LA so far?" Acceptance rates for returning LAs are high and are based more on performance in the LA program than on the persuasiveness of the application itself.

In the initial phase of this study, we did a preliminary analysis of approximately 50 applications from 30 LAs over three semesters (Fall 2012 through Fall 2013), paying particular attention to changes in an individual LA's applications over time. This analysis shaped our interview protocol (see below) and informed a more systematic analysis of applications from the following year. For the analysis presented here, all returning LA applications for Spring 2014 and Fall 2014 were analyzed; in addition, some earlier applications were analyzed for LAs who were selected for interviews. This phase of analysis included 38 returning LA applications from 29 unique LAs. These LAs are a subset of the 61 LAs whose teaching reflections are included in this analysis.

\section{Interviews}

A subset of LAs (12 total) have participated in loosely structured clinical interviews about their experiences in the program. Interview subjects were selected to include diversity of major, career plans, and length of experience in the LA program. For this analysis, we include only interviews of LAs with more than one semester of experience in order to characterize the cumulative impact of multiple 
phases of experience in the program. Nine of the 12 interviewees met this criterion; of these, three were women; one was African American, one multirace, and one unknown ethnicity, and the remaining six were White. (We note that for the first two semesters of the program, the percentage of Hispanic LAs was low-between 10\% and $13 \%$ - as was the percentage of Hispanic physics majors during the previous two years; both numbers increased significantly over the following three semesters.) Seven of these interviewees are also represented in the returning LA application data. All interviews were conducted by the second author, a White woman who is a nontraditional undergraduate student, in her mid-30s, majoring in physics. The interview protocol includes questions probing both self-perceptions (e.g., What parts of being an LA are you particularly good at? Has being an LA made you more competent at other things besides teaching?) and practice (e.g., Do you use the Help Center to study or hang out? Do you interact differently with faculty since becoming an $L A$ ?). Adjustments were made to the interview protocol both during individual interviews, in response to the participant's experiences and reflections; and between interviews, in response to emergent subthemes in the data.

\section{B. Analysis methods}

Video records from interviews were collaboratively analyzed for insight into the impact of the LA program on participants' construction and perception of identity, using the blended identity framework as an analytic lens. Written data were collaboratively coded initially according to the blended framework described above, and then in more detail according to emergent subthemes in the data. For example, as we coded the first few interview records, we found an emergent subtheme we named "okay to be wrong" (described in Sec. V B 6), which LAs expressed as a newly recognized form of competent engagement in the community; a question probing this subtheme was added to the protocol for later interviews, and the subtheme was included in the coding of written data. The processes of data collection and analysis were interspersed, with themes and questions emerging from analyses shaping questions posed in interviews and teaching reflections.

Data sources quoted in Sec. V were chosen for the clarity or eloquence with which they demonstrate the themes discussed. Some themes appeared more frequently than others. While we do not attempt to quantify the prevalence of each theme in this analysis, for every theme described below the data contained more examples than those quoted; similarly, while we describe evidence of shifts in a number of aspects of the lived identity of the LAs in this study, not all LAs experienced all of these shifts.

We note that the data and our interpretations are not cleanly independent of the daily operations of the LA program; that is, we are all deeply involved in the running of the Texas State LA program, and our discussions with
LAs of the purpose of the LA program and the meaning of their experiences are inevitably influenced by our own evolving understanding of program impact. However, through the daily operations of this program, we do not promote any particular way of talking about the program as a whole. In addition, LAs are aware when composing their writing or participating in interviews that one or more of us will be analyzing and in some cases evaluating the artifacts: teaching reflections count towards the grade for the pedagogy course for first-semester LAs (taught by E. Close), and program applications are written with the goal of being rehired for another semester. We discuss each of these issues below.

LAs submit their pedagogy reflections on a "forum" on the course Web site, which is accessible to all students in the course as well as to the instructor; they are assigned to read and respond to at least one other student's post. Reflection prompts are open ended (e.g., "Describe something interesting you have noticed while teaching. What made it interesting to you?"), and in most cases LAs can choose between two or three such prompts. Thus, while students may shape their responses in ways they believe will be read favorably by the instructor, the nature of the assignment is broad enough that students' choices about how to respond provide insight into their ideas about teaching and learning and about how they experience their LA roles. In addition, LAs' responses do not always show strong alignment with LA program values, for example, referring to direct instruction rather than facilitation of dialog ("As I am explaining something to them, I can tell many students are not interested in what I have to say and will say, 'so....am I right or am I wrong."'-Blake, teaching reflection, F12) or describing a failure to implement constructivist instructional strategies ("I tend to forget to ask questions to draw out an answer when I am fully confident in my understanding of a topic [...] My confidence is pushing aside the student's own discovery."Julia, teaching reflection, F12).

Because applications to the LA program are written with the goal of being rehired, it is reasonable to wonder whether LAs express themselves freely in response to questions on the application or if instead they shape their responses according to what they believe we want to see during application review. While this bias may be present in the data, student responses nevertheless provide valuable insight into their experiences. The open-ended nature of the questions on the application (for example, "Why do you want to continue to be an LA?"), combined with the complex and varied nature of the program itself, means that it would not be a straightforward task to determine a "party-line" response even if that were the applicant's goal. In addition, students' ability to accurately represent, and elaborate on, what they believe we want to hear indicates a substantial accomplishment. For example, we regularly discuss the value provided by the LA program-and by 
teaching in general-for continuing to learn physics content. If an LA writes on her application that she wants to continue to be an LA in part because she wants to continue to strengthen her understanding of physics, that indicates that she understands that we consider it not only acceptable but actually expected and valuable for students to think of themselves as learners as well as teachers in the LA context. Similarly, the way in which an applicant elaborates is unconstrained by the prompts, and thus provides insight into some combination of the applicant's experience and what he believes the programmatic priorities to be.

To summarize, the data gathered from these written sources are useful despite possible bias for several reasons. First, LAs do not express only ideas that align with the values of our program. Second, LAs respond to open-ended prompts that require elaboration. Third, many of the ideas about teaching and learning expressed by LAs on their applications are sufficiently countercultural in the broader context of public education that clearly expressing these concepts in their applications indicates significant programmatic impact. Thus, the language used in LA responses and their choices of what to discuss are data that provide valuable insight into their experiences in the program.

\section{ANALYSIS}

In this section, we examine data from the LA program at Texas State University through the analytic lens of the blended identity framework described in Sec. III. While we organize this section into subsections according to the elements of the identity framework, we recognize that these elements overlap and thus some data are analyzed in multiple subsections below. Note that the title of each section $\mathrm{A}-\mathrm{D}$ is in the form $X$ and $Y$, where $X$ is an element from communities of practice theory and $Y$ is the corresponding element from the physics identity framework.

Individuals are members to varying degrees of multiple communities of practice. We focus this analysis on two communities of which all LAs are members: the community of undergraduate STEM majors, engaged in the joint enterprise of negotiating required coursework and obtaining a STEM degree, and the community of physics instructors, engaged in the joint enterprise of supporting students in their learning of physics concepts and skills (see Refs. [16-18]). These communities are not completely distinct, as described in Sec. VD; nevertheless, they are useful as a starting point for our analysis. The elements of the blended identity framework and the corresponding observed subthemes are shown in Table I.

\section{A. Negotiated experience and recognition}

As described above, the physics identity dimension of recognition describes an element of the communities of practice characterization of identity as negotiated
TABLE I. Summary of elements from blended identity framework with themes from data.

Negotiated experience and recognition

Helping students is rewarding

LAs can shape students' ways of learning and interacting

Helping students and participating in LA program strengthens

LAs' own physics understanding

Being an LA strengthens relationships with peers and faculty

Community membership and competence

LAs become more competent and confident in physics

LAs feel like part of a supportive and collaborative community

Being an LA increases teaching competence and reshapes

LAs' concepts of good teaching

Participation in the LA program changes ways of learning and of being a student

Variety is valuable for learning

It is okay to be wrong and to ask for help

Learning trajectory and personal interest

Nexus of multimembership and Integrated physics identity

experience: how others see and respond to us shapes our sense of who we are and what our actions mean. Before their participation begins, all LAs receive significant recognition from more central members of the instructional community through being accepted into the LA program. In addition, many LAs apply to the program because they have been encouraged to do so either by their professor or by an LA, frequently by LAs who serve as laboratory instructors and so have a small group of students whom they know well. Acceptance to the LA program and the new reified identity as "an LA" shapes LAs' self-perceptions before they begin teaching. For example, in the first teaching reflection of the semester, new LAs are prompted to describe their expectations about what will be interesting and challenging about their work in the program; one new LA, Connie, responded "The most interesting thing about teaching as an LA is teaching, because I would never [have] pictured myself as a person that could have that much knowledge for people to come to and learn something useful... Now people are going to ... ask me for explanations and answers that I know and understand." (Note that in this and all subsequent data, pseudonyms are used and any spelling errors are corrected.) In addition to the overarching theme of recognition, several subthemes emerged from our analysis of the body of data we categorized as providing insight into LAs' development of identity as negotiated experience. We describe the themes below and give examples of data illustrating each.

\section{Helping students is rewarding}

A significant percentage of LAs' time in the program is spent in contact with students in the introductory sequence, assisting them with tutorials during class and working with them on homework problems in the Help Center, and in 
some cases supporting them during laboratory instruction. Many LAs describe great personal satisfaction from experiencing the positive impact they have on the students they assist; for example, "My experiences in the Learning Assistant program have made me realize how rewarding it is to help students grasp ideas that were once out of their reach" (Leah, returning LA application, Sp13). One LA wrote "[A student] came up to me after the test and ... credited [his high] score exclusively to my discussion with him on the day preceding the test. That was probably about the proudest I have ever felt in my life" (Mike, returning LA application, Sp13); in his interview nearly a year later, the same LA referred again to this same experience, saying, "that was by far one of the most memorable experiences of my life [...] - knowing you've helped someone, and knowing they're happy for it-giving them confidence in themselves that they can do these things. I think that's really exciting." These descriptions indicate LAs' sense of their positive effect on others: helping others grasp ideas, giving them confidence in themselves. In some cases, LAs refer explicitly to the unique impact of recognition received from students: "...there was a moment in the help center where I was helping a student, and afterward they told me I was good at physics. I don't get that kind of feedback from anywhere and I wasn't expecting it at all" (Kerry, teaching reflection, Sp14).

These positive responses to the experience of being recognized as knowledgeable and helpful are consistent with the relationship found by Hazari et al. [4] between participating in expertlike roles (e.g., answering questions) and self-reported physics identity. Jocelyn, a secondsemester LA teaching mechanics for the second time, gives a detailed description in her interview of an experience working as an LA in which she felt particularly valued. She describes the tutorial homework problem involved, which requires students to construct a set of free-body diagrams for individual links of a hanging chain [10], then tells the story of how she redirected her student's attention from his (incorrect) notes to a collaborative process of making sense of the problem (here $\mathrm{JC}$ is the interviewer and second author).

Jocelyn: ...he'd look back at his notes, which were wrong, and he'd draw the same free body diagram. And I'm like, no, stop! That's not right. I'm telling you that's not right, because you've done it three times in my presence, and it hasn't been right, not once. And he kept doing it, so I just flipped his book closed, and I was like, no, put your book away. We're going to do this, right now, we're going to learn this, and you're going to know exactly how to relate each force to every other force. And, so, we started, and we just... drew out all the gravity, because they were identical links, and from there we compared each force to the first gravitational force... on link four, ...

$\mathrm{JC}$ : Oh, this is the chain, like this [gestures]...
Jocelyn: Yeah, you know what I'm talking about?

JC: I love that one!

Jocelyn: Yeah, it's one of my favorite...

JC: It's hard...

Jocelyn: That one is hard! But, when you understand it, and you can relate them all to the first gravitational force-I mean, all the gravities are the same, but the first gravitational force? It becomes so much easier, and you understand why free body diagrams are important, and why the magnitude is important.

JC: Right.

Jocelyn: And at the end of it he was like, "okay, okay, I buy this." So I erased it, and I was like, "draw it." And he was like ah-hah moment, like he understood it, and he drew it to scale, drew it how it needed to be drawn, and got it right when he drew it back on his page... and it was pretty awesome. I felt pretty valuable.

JC: Cool. And did he say anything that made you feel that way? Or you just did, because you knew...

Jocelyn: He was like, "I get this now. I was not drawing the right thing." And I was like, "No, you weren't." And he was like, "But, this makes more sense."

In her description, the value Jocelyn perceives herself to have is as someone able to help a student overcome a persistent difficulty; in the narrative she presents herself as someone with the authority to direct the student's attention ("so I erased it, and I was like, 'draw it") and the skill to help him understand an important physics concept ("We're going to do this, right now, we're going to learn this"). What made her feel valued was not being told that she had been helpful, but the experience of guiding the student to the correct understanding and hearing him say that the physics made sense; that is, she encountered the effect of her interaction with the student, and the effect was meaningful to her in a positive, valuable way: the student reached an understanding of a physics problem she enjoys ("it's one of my favorite...") and that she believes to be important. Note that this exchange during the interview also makes visible the instructional repertoire shared by Jocelyn and the interviewer (an experienced LA herself), and also their shared enthusiasm for the value of the particular problem being considered in the instructional episode Jocelyn describes.

\section{LAs can shape students' ways of learning and interacting}

An extension of being recognized as having valuable content knowledge expertise is the experience described by a number of LAs of guiding students into new ways of interacting with each other and with the course materials and tasks. Near the end of his first semester as an LA, Tom wrote "I understand that physics takes time and patience and I try to communicate that with the students I work with. When they see me as one of them, they open up more and genuinely engage in the learning process" (returning LA 
application, Sp14). Tom perceives that his ability to shape students' attitudes toward their physics work while simultaneously being "one of them" allows him to powerfully and positively influence students' forms of engagement in ways faculty might not be able to do. Similarly, Fiona wrote in her final teaching reflection, "I took a student to [a professor's] office multiple times when I didn't know how to completely solve a problem and I think that was very helpful. Not only in solving the problem but I think exposing the students to going to a professor's office and asking for help will make them more willing to go to office hours and ask for the professor's help" (F14). Jacob wrote "[Students] know I'm not afraid to ask for help if I need it, which helps encourage them to do the same when they need it" (returning LA application, Sp14). Here Jacob frames needing help as a valid part of the learning process, and Jacob and Fiona both describe asking for help as something less experienced students may be afraid of, which positions their acts of asking for help as modeling expertlike behavior for introductory students.

This impact on the students with whom they work provides LAs with an experience of being regarded not only as knowledgeable in the content students wish to learn, but as models for the kinds of actions to take in order to learn the content, an even more expertlike position in the community. One LA connects his experience explicitly to the experience of community and his role in it: "I love working in the help center with a group of students and watching the group eventually help each other out. It's almost like watching the physics community grow, which is awesome" (Matthew, returning LA application, Sp14). The experience of community membership will be examined in more detail in Sec. V B.

\section{Helping students and participating in LA program strengthens LAs' own physics understanding}

Most LAs reflect at some point on the value of the LA experience for their own understanding of physics. In his interview, Mike offered that being an LA had made him a better communicator; when asked by the interviewer whether being an LA had made him better at anything else, Mike responded "It made me better at physics, that's for sure." Another LA wrote after two semesters of experience that he loved being an LA because "I get to help out the people who want help, [and] I have gotten the opportunity to hone my own physics and communication skills" (Jacob, returning LA application, F14). This strengthening of LAs' content knowledge is consistent with research on LA programs at other institutions and is an explicit goal of the Texas State LA program; when recruiting new LAs, we often share data from CUBoulder showing that their experienced LAs score nearly as well as their physics graduate students [6], and we promote the opportunity for increasing physics understanding as a benefit of applying to the LA program.
Some LAs experience tension between the role of expert they are taking on as peer instructors and their understanding of how much content knowledge they are (still) learning. New LAs express this in their first teaching reflection, when prompted to describe what they think will be most difficult about participating in the program: "One of the most difficult things for me teaching as an LA will be insufficient explanations or stumbling into a subject that I realize I don't understand as much as I thought I did. The last thing I want is to be asked a question by a student and give them the wrong answer because I don't know what I am talking about" (Shelby, Sp14); "The most difficult thing about teaching as an LA will be getting over the fear of not knowing how to answer a question" (Christine, Sp14). One resolution to the fear Christine describes is the realization expressed by many LAs that they do know how to begin to find the answer. For example, near the end of her first semester as an LA, Natalie reflected "I have gotten better at listening to the student. [...] [Online homework problems] used to scare me if they came in looking for help with it in the tutoring center, and now it's still intimidating but I feel like I have a much better handle on it because [...] I know I can figure it out" (teaching reflection, Sp14). Here Natalie is no longer as worried about failing to have relevant content knowledge at her fingertips, because she has become skilled in listening carefully and helping students "figure it out." Similarly, Hannah, wrote about being nervous when asked to help with an unfamiliar problem, "but when I remembered what Dr. Close said to us last week, 'That we are not solution manuals, and we are there to help students think about the problems, not do it for them.' This really helped calm me in my nervousness, and through trying to play with the information given, we were able to [...] find our way from there" (teaching reflection, Sp14). Hannah described this both as a shift in her own expectations of herself and as a rewarding interaction with the student: "By being more aware of my problem solving skills and role as an LA I was able to perform the best I could, and I could tell I truly made a difference in her day."

Thus, LAs negotiate the meaning of their interactions with students in terms of dual roles- "expert" and "peer learner"-and reconcile the potential conflict between these roles by reframing or renegotiating their responsibility to students: if their role is to help students think clearly and figure things out, then they have relevant skills (listening, figuring things out) and can at the same time deepen their own content understanding (figuring out alongside the students, and considering problems from new perspectives).

\section{Being an LA strengthens relationships with peers and faculty}

Identity as negotiated experience is characterized by encountering others' perceptions of who we are and of the meaning of our own actions. LAs are recognized by faculty 
as members of the community of instructors assisting with the educational mission of the department; LAs also work closely with each other within the structures of the program. Thus, the experience of being an LA includes closer contact and more interaction with faculty and with peers than most have experienced prior to being accepted into the program. This provides opportunities for LAs to strengthen their relationships with their peers as well as with faculty. Many LAs describe this as an important element of their experience in the LA program. For example, near the end of her first semester as an LA, Brooke described her expanded sense of access to other members of the physics community in terms of the help available to her: "One of the things I really enjoyed about [being an LA] was that I became way more involved in the department and I feel like I have a larger network of help if I need it because of it" (returning LA application, Sp13). This is particularly notable because Brooke was already an advanced physics major when she joined the LA program. Hannah, an engineering major who joined the LA program while still taking introductory courses, also expresses the importance of the relationships she developed through her participation: "Becoming more engrossed in the physics department has allowed me to establish rapports with professors, other tutors, and my fellow peers, giving me that sense of belonging in science, which I desired" (teaching reflection, Sp14).

Some LAs express not only the importance of this element of the LA experience, but also its unexpected nature: near the end of his first semester in the program, Mike, a computer science major, wrote "I am naturally shy and introverted person; so, at first, it was a little difficult for me to break out of my shell... However, as I began talking with the students and other LAs, I immediately realized how comfortable I feel teaching or talking with my peers" (returning LA application, Sp13). The words "realized how comfortable I feel teaching or talking" indicate shifts in Mike's perceptions of self in relation to other students; in his application for a subsequent semester, Mike includes relationships with faculty as an important element of his LA experience: "this program has led me to connect with some of the best and most welcoming people I have ever met (both faculty and students)" (returning LA application, Sp14).

In their descriptions of the meaning of the LA experience, both Mike and Brooke illustrate the importance of their membership in both student and instructor communities of practice. These features will be addressed in the following sections.

\section{B. Community membership and competence}

As described in Sec. III, identity as community membership is experienced through competent engagement in the shared repertoire of the community. As with negotiated experience, we organize this section according to subthemes emerging from our analysis.

\section{LAs become more competent and confident in physics}

In our analysis of identity as negotiated experience above, we discussed LAs' experience of finding their own competence increasing as they enacted their LA roles by helping students. LAs also reflect more directly on the development of their own understanding and their success as physics students; for example, "I find myself discovering new things about a topic I felt I fully understood" (Jacob, returning LA application, Sp14), and "I'm pleased with my grades in physics and I think that the LA program has definitely impacted my ability to succeed in these classes" (Leah, returning LA application, Sp14). In his last teaching reflection, one first-semester LA described his development of competence in scientific reasoning: "The major take away for me in being an LA is the development of the reasoning skills that being a scientist demands" (Noah, teaching reflection, F14). He elaborates on the source of this change: "I think the mechanism for growth that prevailed was one of mutual curiosity: when working on a tutorial and the answer did not immediately come to my mind, I was given an opportunity to brainstorm and explore various ideas that I and the students could muster in order to use reason to argue for which idea fit the question best."

Noah identified his growth in competence as developing during productive interactions with the students in the introductory course. Other LAs identify the student community available to them through their participation in the LA program as a mechanism for their increased competence: "I feel that being an LA is helping with my performance in my waves and heat class in many ways, both directly (furthering my knowledge of the subject) and indirectly (connecting me to other people within the program that have or are currently taking the class)" (José, returning LA application, Sp14). The relationship between competence and community membership is addressed in more detail in the next section.

\section{LAs feel like part of a supportive and collaborative community}

Most LAs discuss the value of feeling part of a community; in some cases they describe the community as "the LA community" or "the community of students and faculty"; in other cases LAs use the phrase "the physics community" or "the department," which seems to include both faculty and students. LAs describe the value of community membership in a variety of ways, including the network of support available- "One of the best parts about being an LA is how much more comfortable I have become approaching professors with questions. I love the community and the academic benefits from being an LA" (Matthew, returning LA application, Sp14) —as well as the more general sense of positive affiliation: “... I love this 
department. The other LAs, the teachers, the building, it has become a part of my life and is very important to me, and I want to be a part of it in every way I can, and being an LA is a fantastic way to do so" (Luis, returning LA application, Sp14).

Some LAs describe how being in the program has connected them to a broader community that has helped them in ways beyond the LA program itself. For example, José wrote "my time spent as an LA has helped me become a greater part of the physics community by introducing me to groups like [the Society of Physics Students]" (returning LA application, Sp14). Jocelyn describes the LA community as helping her learn that "I need need need to start planning ahead" for internships and research, "to prepare for my future career and also just to better myself" (returning LA application, F14). In her interview, she describes how joining the LA program impacted her positively in multiple ways, centered around being part of a community: "It's pretty cool to have, like... like, I have my friends that aren't in the physics community, but I have, like, physics community friends. [...] I'm completely part of the community. I have friends in there, in the program. In classes right now, I go and I help students and I know them by name, and that's pretty awesome... I have supervisors I can go to as an employee, as a student, as someone who just kind of needs advice at the time. I feel like, that whole thing is pretty awesome." In response to a follow-up question asking whether being part of the physics community has helped her as a student, Jocelyn says "So, my semester before being part of the LA program, I had like a 1.7 GPA for that semester. My first semester of being an LA, which is last semester, I had a 4.0. Do you understand how dramastic that, like...I had the time to actually put into school that I need to be putting into it. I'm part of a community."

Jocelyn's description of the community she feels part of includes supervisors (faculty), peers, and students in courses she assists with, and encompasses her roles as student, physics major, and instructor; she describes membership in this blended community both as personally positive ("awesome") and as instrumental in a great increase in her performance as a student.

\section{Being an LA increases teaching competence and reshapes LAs' concepts of good teaching}

Not surprisingly, participation in the LA program increases LAs' perceptions of their competence in teaching physics. In his interview, Mike describes the LA program as making him a better communicator, a skill he considers critical to effective teaching. On her returning LA application for Fall 2013, Leah demonstrates that she is both familiar and comfortable with elements of the instructional community's shared repertoire: "In the past two semesters of being an LA, I've learned how to communicate more effectively ... If someone doesn't understand a concept when I explain it verbally, I can draw them a picture or a diagram instead. If they can't verbalize what they're thinking themselves, sometimes handing over a marker so they can draw something out for me will help me understand where they're at in their understanding of the material." Another LA, a transfer student who had no experience with tutorials or reform instruction prior to joining the LA program, describes asking more experienced members of the community for guidance in improving his instructional skills: "One area of the LA job where I have been learning a great deal is in preparing the tutorials in a way that is the most helpful for helping students. When the semester started my exposure to tutorials was very limited, so the priority at first was just making sure I was doing them right. But when I took those answers into the classroom I found that they didn't help me much when addressing student issues. So, I learned pretty quickly to make sure I was letting ... other experienced LAs (or actually asking them) to share with me other ways to describe answers" (Jake, returning LA application, F14).

In the quotes above, both Jake and Leah describe an experience of increasing their teaching competence by expanding the range of approaches they can use to explain correct physics to their students. In her application for the following semester, Leah describes increased competence with a less familiar aspect of teaching: "I'm finally feeling comfortable in a role where I help them think instead of boiling everything down to 'right' or 'wrong." This illustrates an additional change in LAs' perceptions of teaching: participation in the LA program changes what LAs perceive as effective teaching strategies and what they view as excellent instruction. Leah's description of learning to "help them think" shows a new respect for students' ability to construct their own understanding, and a corresponding shift in what she sees as her role in helping students learn. Other LAs describe a similar shift, for example, "After spending so much time working with other students and explaining things I believe I have become a much better listener. Often it is much more helpful to just be an active listener to a student who is trying to hash out a problem" (José, returning LA application, Sp14).

In her interview, Brooke, a senior physics major and experienced LA, describes changing her conception of good teaching through readings in the pedagogy course as well as through observations in the "lecture" classroom. She responds to a question about her experience tutoring prior to joining the LA program by contrasting her teaching methods before and after becoming an LA, describing her few experiences with tutoring as feeling "like I was just... talking at a wall. And like, it didn't feel like it was really interactive at all, it felt like it was me just...trying to smash something into their head..." She reflected on how reading research articles in the pedagogy class convinced her that "there's really something to this. I need to embrace this and run with it," and then continued, "You know, one of the 
other things that made me want to take hold of it and run with it was watching Eleanor [Close] teaching her classes, before we would actually, you know, break off into groups and things like that. I was just like, man, the way she teaches is really really interactive, and this is way more engaging than any other course I've seen. This is way more engaging. And this is more fun as a consequence, and it seems like people are going to be way more receptive to this than anything else, because they're not bored." This is an example of what Lave and Wenger [3] named "legitimate peripheral participation": Brooke's LA experience enabled her to observe and emulate an expert engaging in the same enterprise (teaching) with which she was assisting in a peripheral but still authentic way, and as a result she learned to both value and enact a more student-centered teaching practice.

\section{Participation in the LA program changes ways of learning and of being a student}

In addition to changing LAs' understanding of good instructional practice, as described above, participation in the LA program impacts LAs' perceptions of valuable practices for their own learning. Many LAs describe ways in which they have changed their learning behaviors as a result of their LA experience. In his interview, Alan describes the change in his approach to learning as fundamental: "It's changed the way I try to learn things. It's made me [15 sec. pause]... I feel like I said before-I'm not just looking for similar symbols, I'm realizing what's going on in the problem. So even if I haven't seen a symbol before, I can tell what it's at least talking about, or referencing to." This description fits with a shift from a focus on finding answers, associated with a "school science" framing, to a focus on meaning making consistent with the LA program emphasis on interactive and conceptual learning. Alan describes this as one of his favorite things about being an LA.

Other LAs describe the influence of the LA experience on their approach to applying concepts in problem-solving aspects of their work as STEM students. In her final teaching reflection of her first semester, Alexa wrote, "I have used what I have learned as an LA in all of my studies. First, I become familiar with my own mental models and then I compare these to what is known to be true. Being an LA has taught me that being able to recognize your own inherent beliefs and intuitions when learning a new concept is extremely important when learning a new and difficult concept" (F14). In his interview, Mike, a computer science major and third-semester LA, describes in more detail how being an LA has made him a more metacognitive learner: "I think the ability the LA program has given me [is] when I'm studying on my own, to treat myself as both the tutor and the tutee. From the tutor perspective, look at myself as a tutee and say, okay, what am I struggling to understand here. Can I ask myself questions that I would ask a tutee, and derive $[\ldots]$ where the failure to understand actually lies." He attributes this ability both to his experience in helping other students- "you have to be able to put things into-into definitions that you wouldn't necessarily use [...] so it teaches you to have to be a bit more vicarious and think about the way other people see things"-and also to his increased awareness of his own learning process: "I think [what] that created for me was metacognitionthe ability to think about how I think about things, or how people in general think about things. And that, to me-If I'm struggling with a concept, I can think about, you know, what am I doing wrong here, why am I not thinking about this correctly, what can I do differently to understand this concept. .... and I think that's directly related to teaching in the LA program."

Mike's description of how being an LA has given him tools to manage his own learning, particularly in times when he does not yet understand a concept, references both his teaching experiences and perhaps also his experience in the pedagogy course, which includes a reading and discussion focused on metacognition. Other LAs also describe using more metacognitive process in their own learning; for example, "I learned to be patient when trying to solve a physics problem; I have learned to avoid knee-jerk or wild-goose-chase approaches to physics. I used to read a problem and then quickly go to the kinematic formulas and try them all to see which one would work. Now I have a planning period where I really do think about the best way to approach a particular situation" (Tom, returning LA application, Sp14). Note that the term "wild-goose-chase" is used in the article on metacognition assigned in the pedagogy course. José, a junior physics major, makes a similar statement: "I have also learned to really work on understanding the concepts behind physics problems and formulas. Before I was an LA I would essentially just plug and chug my way to answers" (returning LA application, Sp14). One aspect of metacognition is being aware of different possible approaches to understanding new scenarios; this element of the LA experience is described in the following section.

\section{Variety of perspective is valuable for learning}

LAs adjusting to assisting with a more constructivist, less transmissionist model of instruction often reflect on their developing skill in looking for value in students' ideas. Natalie, a physics major still in the introductory sequence, wrote at the end of her first semester as an LA, "I have learned to be more patient with students and that just because someone might be thinking of something a little differently doesn't mean it is wrong" (returning LA application, F14).

In addition to being valuable as a tool for supporting student learning, LAs describe the practice of recognizing a variety of ways of conceptualizing or approaching a situation as useful for their own learning. Near the end of 
her third semester as an LA, Leah wrote, "I have also learned something new from students every semester I've been an LA; they always bring up new questions and new ways of looking at things that I hadn't considered before and it helps me to broaden my views and think about problems in new ways. Instead of building rigid definitions, I'm able to think in a more complex way about physics" (returning LA application, Sp14). In her interview, Brooke, a senior physics major, reflects on coming to value multiple ways of sense making: "That was one of those things where it's like, in physics as a whole, physicists love that. They love being able to come up with the same answer through totally different thought processes. But before becoming an LA that was something I didn't really care for-I was always just like, why am I doing this? I'm just coming up with the same number again. This just feels like I'm doing double work for no reason. But it's something that...I have a lot more respect for now." It is notable that Brooke associates this practice primarily with "physicists," and only secondarily with constructivist teaching methods, suggesting that she sees this practice of the LA program as well aligned with the practices of the broader community of professional physicists. She continues to describe how this has benefited her own learning: "If I try something one way, and I can't quite seem to get it, then I'm much more able to be like... okay, let's just not think about that any more. Let's try a totally new approach, and start with some other formula, or some other concept, and see if I can get it. And so it's made me a little more flexible in trying to do my own physics problems." Brooke identifies her experience in the LA program as causing her to become a more flexible thinker, which enhances her success in her senior-level physics coursework and aligns her values more closely with those of professional physicists.

\section{It is okay to be wrong and to ask for help}

Perhaps the greatest shift in LAs' identity through membership in the student and instructor communities of practice is the change they describe in their perceptions of what demonstrates competence. In their returning LA applications, a number of LAs describe learning that asking for help does not demonstrate incompetence, but rather is a normal part of competent participation in the community in which everyone is learning: "Probably the biggest thing I've learned from the LA program is how to ask for help. Previously, I would be embarrassed if I didn't know something and now I have no problem going either a supervisor or another LA for help when I need it" (Jocelyn, Sp14); "Another thing I have also learned to do is be able to admit I don't know, and not be afraid to walk up to a professor and ask a question. It's amazing how much that part of me has changed over the semester" (Matthew, Sp14). LAs encourage each other in this shift: in response to a teaching reflection by a fellow LA struggling with electricity and magnetism questions in the Help Center, one
LA posted "We are all learning and not knowing how to do something right away whether you've already taken the class or not doesn't say anything bad about you. It only highlights the fact that we are all on a track to better understanding!" (Andrew, F14).

In addition to learning to acknowledge rather than conceal gaps in their knowledge, these LAs have changed their practice in a way that increases their level of interaction with faculty and fellow students. Another LA explicitly describes both learning to ask for help and the positive impact this increased interaction has had on his learning: "I have also learned to just ask questions when I need help with something. In the past I generally worked on most homework by myself which made things much more stressful when you get stuck. Now, I feel like I learn things much more efficiently since I often ask for help when I'm stuck" (José, returning LA application, F14).

The statements above show a new acceptance of getting stuck as a normal (not embarrassing) part of the learning process. Some LAs express an even greater shift: not only is it normal and acceptable to get stuck, it is normal and even productive to be wrong. According to this view, mistakes and errors in reasoning are not only an acceptable part of participation, they can actually contribute to valued community goals. For example, Gavin, an upper-division physics major with two semesters of experience as an LA, says in his interview, "I feel like one of the goals of the LA program is to teach students that it's okay to make mistakes-it's even good if you can recognize that you're making mistakes." Another LA makes a similar statement in near the end of his third semester in the program: "So far, the LA program has taught me the importance of making mistakes. Making mistakes is one of the key events that lead to understanding. One must make mistakes in order to learn, because being incorrect (and realizing it) illustrates one's misconceptions and corrects them" (Mike, returning LA application, Sp14).

These statements reframe making errors as a valuable part of learning physics; in his interview, Alan, a juniorlevel physics major in his third semester as an LA, describes how learning that it is okay to be wrong has been helpful both in his own coursework and in his work as an LA. In response to the question "What do you like most about being an LA?," Alan responds, "I think it's helped me be okay with being wrong [...]. Which is a lot less frustrating when I'm doing homework-well, I'm still frustrated when I do homework, but... when I'm helping people in Help Center, and I'm not sure what the answer is, I'm okay with getting another LA and working through it with the student $[\ldots]$ and I think that makes them more comfortable asking questions, because they don't - they're not intimidated by us as much as they are when the instructors are there." It is noteworthy that Alan's response here is not only something he feels he learned through his experience as an LA, it is his favorite part of being an LA. 
This suggests that the shift in competence beliefs illustrated by the statements above has a powerful and positive impact on LAs.

Both Gavin's and Alan's interview responses and Mike's reflection above suggest a shift away from a model of competence centered on demonstrating the ability to obtain correct answers. This correct-answer orientation is consistent with a traditional "school science" that emphasizes "being smart," understanding quickly, behaving well, and getting good grades [20,21], and with the "fixed mindset" associated with performance goal orientation and the entity theory of intelligence [22,23]. In contrast, these LAs have learned to value and enjoy interactive, logical exploration and argumentation as a rewarding way of relating to each other, to students, and to faculty. This communal practice repurposes being wrong (or saying wrong things) from a form of incompetence to an important component of competent engagement, within a practice that recognizes multiple forms of competence. Dweck [22] explains that "retraining children's attributions for failure (teaching them to attribute their failures to effort or strategy instead of ability) has been shown to produce sizable changes in persistence in the face of failure, changes that persist over time and generalize across tasks." In fact, the practice of interactive, logical exploration and argumentation is facilitated in part by "failures" of knowledge, in which LAs make incorrect physics statements. So, not only is feedback about failure within interactions in the LA program directed more toward effort and strategy than toward ability, but the "failure" can be understood as successful in the sense of stimulating a fun and interesting discussion. The data we present here do not directly support the idea that LAs find such discussions enjoyable regardless of whether they are right or wrong; however, we know from our lived experience in the program that LA preparation sessions often involve playful comments that extend from, relate to, and inform the serious work of preparation that they do. LAs' comments about friendships and community in Secs. VA 4 and VB 2 are consistent with this image of joyful community activity.

\section{Learning trajectory and personal interest}

As described in Sec. III A, identity is constantly renegotiated; changes in our identity over time build a sense of trajectory - a sense of where we have been and where we are going. Identity as learning trajectory incorporates past identities and possible futures into making meaning of the present. LAs who are (or become) interested in teaching at the K-12 or college level describe participation in the LA program as valuable for contributing to realizing that interest. On his initial application to the LA program, Mike described a possible future he believed would be positively influenced by participation: "For me, I think that this would be an awesome opportunity to test my ability as a teacher. Since I started at Texas State, I have dreamed of one day becoming a professor." His subsequent applications continue to refer to this dream, and to the value he sees in the LA experience for supporting that possibility. Other LAs also reflect on how the LA experience supports and shapes their future interest in teaching; for example, "Being an LA has been a blessing and a valuable experience, especially because I will eventually be in academia and expect to be an effective professor in the classroom. Knowing the benefits that come from interactive learning I will definitely be implementing group learning into my curriculum. As a student, I have found myself sitting in class wondering how I can apply this technique to engineering classrooms" (Doug, teaching reflection, F14); "Like I mentioned before this experience has helped me make up my mind about getting my teaching certification and teaching" (Connie, teaching reflection, F14). For these LAs, the experience is relevant for the trajectories they have already identified as valued.

Leah, on the other hand, experienced a significant shift in what she perceives as a possible future as a result of her participation in the LA program: "After having experience teaching this semester, I am considering working as a K-12 teacher after college because I've enjoyed how rewarding teaching has been this past semester" (returning LA application, Sp13). On her initial application for the LA program, Leah listed her major as electrical engineering and expressed interest in a biomedical engineering career; a few months later, she switched her major to physics, and her subsequent returning LA applications expressed a growing interest in a career in K-12 teaching: "I think I learn something new every semester, whether it's a physics concept or a better way to teach. I want to continue learning both the actual physics and better methods of communicating the information since my hope is to become a physics teacher after college" (returning LA application, Sp14). Thus, unlike Mike and Doug, Leah's interest in teaching was initiated by her LA experience.

Those with an interest in careers other than education also express the value of the LA experience for their learning trajectory, including development of supportive relationships and strengthening of content knowledge. Jocelyn writes:

Every semester as an LA I learn something new, whether it be about myself, or physics in general. Being an LA has helped me in so many ways that it's hard to put it into words. For starters, I need to continue being an LA to continue to help eliminate gaps in my knowledge in the intro Physics sequence. The second most important reason would have to be how being an LA affects my performance in my other classes-as I tend to do better and have more time to complete assignments. Lastly, I feel like I'm a part of such an amazing community. I absolutely love being a part of a community where I 
can be professional, but also have fun while doing it. It's great! (returning LA application, Sp14).

Like Jocelyn, Alexa describes the LA experience as enjoyable and as integral to her experience of being a thriving physics major: "Overall, I am so incredibly happy that I have found something that I am passionate about. I can't see myself spending my time any other way, which is how I know that I've picked the right major and that I've found my home among the Texas State Physics community. Being an LA has helped me to embrace learning and I can't wait to keep moving forward in this field!" (teaching reflection, F14). Alexa wrote this near the end of her first semester in the LA program, during her sophomore year and while completing the second course in the introductory sequence; she sees the LA experience as instrumental to her long-term goal of becoming a research physicist.

\section{Nexus of multimembership and integrated physics identity}

As stated above, LAs are members of multiple communities of practice, including what we have identified as the community of STEM majors and the community of physics instructors. Identity as nexus of multimembership is defined by the work of reconciling forms of membership in different communities. In previous analysis [16-18], we describe the LA program as creating an overlap between the two distinct communities of STEM students and physics instructors. LAs are members of both communities, which creates continuity and permits "brokering," the transfer of elements of one practice into another (Ref. [1], p. 109); this transfer enriches and improves the functioning of both communities. Brooke, a senior physics major, illustrates this transfer when describing her experiences of increased competence as a result of her participation in the LA program during her interview. She states that she holds herself to a higher academic standard than she had before joining the LA program, and reflects on what caused that change:

Brooke: [The LA program] has definitely encouraged me to, like, try harder overall. Like, not... not that I didn't necessarily try before, [...] but it definitely kind of inspired me to like, you know, take more pride in my work. And, you know ... I guess it's kind of challenged me to hold myself to a higher standard than I used to. JC: What do you think caused that? Like, why do you do that, when you didn't before?

Brooke: Well, I think it was because, you know... I was expecting it of my students. And, if I want my students to do well-which I did - then it was one of those things where I was like, you know, I guess it would be really hypocritical of me if I weren't doing the same thing. How can I ask them to do this if I'm not?
JC: Okay. Umm... Why do you think that you were holding your students to a higher standard?

Brooke: It wasn't necessarily... a higher standard-it was just that, you know, I was giving the course outline, and like, this is what you have to do to get an A, and things like that... and, you know, it's frustrating when a student doesn't do well. Because you think that it-I always have this feeling that, if a student doesn't do well, then it reflects badly on me, because apparently I'm not doing something correctly. Now, I know that's not necessarily the case...because, you know, that's what I was doing. But, you know, I was kind of thinking about it from that perspective, and I was like: I wonder if $m y$ professors get frustrated with $m e$, because I'm not doing those things.

In this segment we see that Brooke identifies both as a student and as an instructor, and that her experience in reconciling her membership in those two communities leads her to change her sense of her own responsibilitythat is, she felt called to improve her performance as a student both because of her responsibility to set an example for her own students and because of her identification with the viewpoint of her professors. We believe this shows that Brooke experiences an integrated physics identity, incorporating values and practices from both the student and instructor communities into her experience of being a physics person.

Another LA, Hannah, describes a similar reconciliation of multimembership in a reflection assignment near the end of her first semester in the program, which was spring semester of her sophomore year:

The most unexpected by-product of being an LA was that I truly was able to solidify my identity in science. My freshmen year as an engineering student, I unfortunately was unable to feel the sense of community among my engineering peers [...]. Becoming more engrossed in the physics department has allowed me to establish rapports with professors, other tutors, and my fellow peers, giving me that sense of belonging in science, which I desired. By having this amazing opportunity to work alongside people who are truly passionate about physics and science, I have been able to realize my potential in the field. Being surrounded by encouraging people has been uplifting and incredibly motivational for me. The role of an LA for me, has been more than just a job, it's been a life changer. (Hannah, teaching reflection, Sp14).

Her description of "work[ing] alongside people" in her LA role, where the "people" include other STEM majors and physics faculty, illustrates Hannah's feeling of belonging to the instructor community of practice. The reference to her "fellow peers" and her description of realizing her "potential in the field," on the other hand, describe her relationships and trajectory within the community of 
physics and engineering majors, perhaps extending to professionals in the engineering field she aspires to join after graduating. These references are intertwined in her reflection, showing that Hannah's integration of her membership in student and instructor communities has given her a sense of belonging to the larger-scale science community, which encompasses STEM majors, physics LAs and faculty, and professional scientists.

As noted in Sec. III C, our current analysis is focused on common themes and shared experiences across the community of LAs, and our discussion of multimembership is therefore limited to the communities of practice common to all LAs. In particular, we did not ask LAs for reflections on the ways in which their race, ethnicity, and gender shape their experiences in the LA program and influence their development of physics identity, nor did we find these themes in the data sources used for this study. However, these issues regularly arise in conversations within the LA community, both in the pedagogy class and in more informal settings. For example, during a class discussion of stereotype and bias, an African American LA described a group of friends telling him he was "not really Black" because he chose to major in engineering; a junior-level physics major discussed the experience of having been systematically ignored by her male group members in introductory courses, even though her ideas were more often correct than theirs. The Texas State LA program provides opportunities to study relationships between physics identity development, LA program participation, race, ethnicity, and gender, as well as family characteristics such as first-generation college status and socioeconomic stability. We will address these relationships in future research.

\section{SUMMARY}

The purpose of this study has been to examine the process of transformation that results from participation in the Learning Assistant program in the physics department at Texas State University, and thereby to contribute to the understanding of LA programs in general and what might make them effective in different ways. In our analysis, we find that the blended theoretical framework based on community of practice theory [1-3] and the physics identity framework $[4,5]$ is a productive lens for characterizing the ways in which the LA experience impacts participants' self-image and enacted identity.

Identity as negotiated experience is the experience of making sense of how others see and respond to us, including ways in which they recognize us as competent or valued. Several subthemes within this characterization of identity emerged in our analysis of LA data: helping students is rewarding; LAs can shape students' ways of learning and interacting; helping students and participating in LA program strengthens LAs' own physics understanding; and being an LA strengthens relationships with peers and faculty. Overall, the data show that LAs experience numerous opportunities for positive recognition from both students and faculty.

Community membership defines identity through the forms of competence developed and valued by participants in the community of practice. LAs experience shifts in their own competence through growth in both expected and unexpected dimensions. The subthemes LAs become more competent and confident in physics, LAs feel like part of a supportive and collaborative community, and being an LA increases teaching competence and reshapes LAs' concepts of good teaching represent growth in areas associated with core functions of the program: collaboratively preparing content and learning and practicing research-based instructional methods. Through participation in these program elements, LAs also change their understanding of their fundamental role(s) as university students (participation in the LA program changes ways of learning and of being a student), the value they place on understanding other people's ideas (variety of perspective is valuable for learning), and their conception of what it means to be competent (it is okay to be wrong and to ask for help).

Identity as learning trajectory incorporates past identities and possible futures into making meaning of the present. Through their exploration of issues of physics learning and teaching and their close contact with physics faculty and students of all levels, LAs have many opportunities to connect their past experiences as learners and their future aspirations as STEM professionals and educators.

Identity as nexus of multimembership is defined by the work of reconciling membership in different communities. As members of both physics instructor and STEM major communities of practice, LAs create continuity and facilitate the transfer of elements of one practice into another, enriching and improving the functioning of both communities. Through the experience of participation in this blended community, LAs develop physics identities integrating a wide range of skills of learning, teaching, and incorporating and valuing diverse perspectives.

\section{CONCLUSIONS AND IMPLICATIONS}

Lave argues that schooling in the contemporary era is characterized by "the decomposition of activity to the point of meaninglessness and the formation of informal communities of practice" (Ref. [2], p. 78). Knowledgeable skill is commoditized: transformed into a "thing" to be transmitted and acquired, rather than a natural consequence of centripetal participation in a community of practice. As a result of this commoditization of knowledge, schools do not provide students with the possibility of genuine participation in ongoing practice. Identity construction is therefore alienated from officially sanctioned classroom activity, and instead takes place in unofficial, "interstitial" communities of practice, which may be unrecognized, 
misrecognized, or subject to institutional disapproval. From this perspective, the community of STEM majors is defined by the comprehensive goal of obtaining a STEM degree and the joint enterprise of negotiating the complexities of required physics coursework and acquiring the institutionally mandated reified content knowledge. The practices required for successfully negotiating university coursework (e.g., cramming for exams, finding homework solutions online) may not overlap significantly with practices that support construction of deep understanding of physics concepts. Through the LA program, however, students have the opportunity to reconcile membership in the STEM major community and the community of physics instructors, whose practices are informed by research on teaching and learning. LAs engage in and transfer these practices, creating a better-functioning student community.

Within the existing structures of higher education, a community-focused LA program provides a mechanism to support students in developing integrated physics identities consistent with productive participation, increased learning, and personal interest in a trajectory within the physics community. The process of reconciling the practices of the two communities may legitimize the educational practices that seem initially to be decomposed "to the point of meaninglessness"; by participating in an instructional community that values collaborative interactions around fundamental physics concepts, LAs learn to repurpose contrived homework scenarios from obstacles to be negotiated to opportunities for valued forms of engagement. Instructional activities therefore become venues for legitimate peripheral participation; LAs transfer the practices of engagement to their own classes and to their engagement with other physics students, improving the local learning environment in multiple ways.

Our analysis suggests that experiences in the LA program support participants' development of integrated physics identity through a variety of mechanisms, including numerous opportunities for recognition, development of competence in physics and in teaching, and structures facilitating engagement in a well-functioning community of practice. If identity formation is critical for recruiting and retaining both physics majors and future physics teachers, as suggested by the work of Hazari et al. [4], then these findings can suggest programmatic priorities for nurturing identity formation and thereby increasing recruiting and retention in the physics major.

In particular, one overarching finding from this study is that there are numerous ways in which LAs' relationships with others were transformed toward an acceptance of themselves and others as having different positions along a continuum of intellectual growth, and toward an abundance of cooperation. In our data, LAs discussed their relationships with students they taught, with their peers as students, with their peers as LAs, with more advanced students, with more experienced LAs, and with faculty both as helpers during learning and as models for teaching. The main implication of this study for LA program design, therefore, is to recognize the importance of the variety of relationships that are relevant to LAs' physics identity development and the conditions under which those relationships may be allowed to flourish. These conditions include, we believe, a variety of teaching and learning situations for LAs to practice in, with varied levels of supervision or immediate assistance from faculty, and varied levels of direct preparation, so that LAs may be allowed to improvise, succeed, fail, and find help from a variety of community members. They also include deliberate efforts to cultivate friendliness and remove fear of being wrong, especially about things that one has already been taught and "should know." Under these conditions, enacting the practices of the LA program allows LAs to productively and joyfully engage in the continuing process of becoming physics people.

\section{ACKNOWLEDGMENTS}

The authors gratefully acknowledge colleague David Donnelly for his support of the Texas State LA program and his assistance with gathering demographic data. The authors additionally acknowledge the anonymous reviewers who provided helpful feedback on the manuscript. This work and the Texas State University Physics LA Program are supported in part by NSF Grant No. DUE1240036, the Halliburton Foundation, and the College of Science and Engineering at Texas State University.
[1] E. Wenger, Communities of Practice: Learning, Meaning, and Identity (Cambridge University Press, Cambridge, England, 1998).

[2] J. Lave, Situating learning in communities of practice, in Perspectives on Socially Shared Cognition, edited by L. Resnick, J. Levine, and S. Teasley (APA, Washington, DC, 1991), pp. 63-82.
[3] J. Lave and E. Wenger, Situated Learning: Legitimate Peripheral Participation (Cambridge University Press, Cambridge, England, 1991).

[4] Z. Hazari, G. Sonnert, P. Sadler, and M.-C. Shanahan, Connecting high school physics experiences, outcome expectations, physics identity, and physics career choice: A gender study, J. Res. Sci. Teach. 47, 978 (2010). 
[5] R. M. Lock, Z. Hazari, and G. Potvin, Physics career intentions: The effect of physics identity, math identity, and gender, AIP Conf. Proc. 1513, 262 (2013).

[6] V. Otero, S. Pollock, and N. Finkelstein, A physics department's role in preparing physics teachers: The Colorado learning assistant model, Am. J. Phys. 78, 1218 (2010).

[7] E. W. Close, L. Seeley, A. D. Robertson, L. S. DeWater, and H. G. Close, Seattle Pacific University: Nurturing physics teachers at a small liberal-arts school, in Effective Practices in Preservice Physics Teacher Education: Recruitment, Retention, and Preparation edited by E. Brewe and C. Sandifer (APS, College Park, 2015), pp. 37-51.

[8] W. K. Adams, K. K. Perkins, N. S. Podolefsky, M. Dubson, N. D. Finkelstein, and C. E. Wieman, New instrument for measuring student beliefs about physics and learning physics: The Colorado Learning Attitudes about Science Survey, Phys. Rev. ST Phys. Educ. Res. 2, 010101 (2006).

[9] K. Gray, D. Webb, and V. Otero, Are Learning Assistants Better K-12 Science Teachers?, AIP Conf. Proc. 1289, 157 (2010).

[10] L. C. McDermott, P. S. Shaffer, and U. W. PEG, Tutorials in Introductory Physics, 1st ed. (Prentice Hall, Upper Saddle River, 2002).

[11] S. L. Adamson, D. Banks, M. Burtch, F. Cox III, E. Judson, J. B. Turley, R. Benford, and A. E. Lawson, Reformed undergraduate instruction and its subsequent impact on secondary school teaching practice and student achievement, J. Res. Sci. Teach. 40, 939 (2003).

[12] D. Hestenes, M. Wells, and G. Swackhamer, Force concept inventory, Phys. Teach. 30, 141 (1992).

[13] S. B. McKagan, R. E. Scherr, E. W. Close, and H. G. Close, in AIP Conf. Proc. 1413, 279 (2012).

[14] R. E. Scherr and H. G. Close, Transformative professional development: cultivating concern with others' thinking as the root of teacher identity, in Learning in the Disciplines:
Proceedings of the 9th International Conference of the Learning Sciences (ICLS 2010), edited by K. Gomez, L. Lyons, and J. Radinsky (International Society of the Learning Sciences, Chicago, 2010), Vol. 1, pp. 388-395.

[15] H. B. Carlone and A. Johnson, Understanding the science experiences of successful women of color: Science identity as an analytic lens, J. Res. Sci. Teach. 44, 1187 (2007).

[16] E. Close, H. Close, and D. Donnelly, in AIP Conf. Proc. 1513, 106 (2013).

[17] E. W. Close, J. Conn, and H. G. Close, Learning assistants' development of physics (teacher) identity, in Proceedings of the Physics Education Research Conference, Portland, 2013 (PERC 2013), edited by P. V. Engelhardt, A. D. Churukian, and D. L. Jones (AIP, New York, 2014), pp. 89-92.

[18] E. W. Close, J. Conn, and H. G. Close, Development of integrated physics identity through physics learning assistant experience, in Proceedings of the Conference on Learning and Becoming in Practice (ICLS 2014), edited by J. L. Polman, E. A. Kyza, D. K. O’Neill, I. Tabak, W. R. Penuel, A. S. Jurow, K. O'Connor, T. Lee, and L. D'Amico (International Society of the Learning Sciences, Boulder, 2014), pp. 1533-1534.

[19] D. MacIsaac and K. Falconer, Reforming physics instruction via RTOP, Phys. Teach. 40, 479 (2002).

[20] H. B. Carlone, C. M. Scott, and C. Lowder, Becoming (less) scientific: A longitudinal study of students' identity work from elementary to middle school science, J. Res. Sci. Teach. 51, 836 (2014).

[21] M.-C. Shanahan and M. Nieswandt, Science student role: Evidence of social structural norms specific to school science, J. Res. Sci. Teach. 48, 367 (2011).

[22] C.S. Dweck, Motivational processes affecting learning, Am. Psychol. 41, 1040 (1986).

[23] C.S. Dweck and E. L. Leggett, A social-cognitive approach to motivation and personality, Psychol. Rev. 95, 256 (1988). 